\title{
Spatiotemporal transmission and socio-climatic factors related to paediatric tuberculosis in north-western Ethiopia
}

\author{
Kefyalew Addis Alene, ${ }^{1,2}$ Kerri Viney, ${ }^{1,3}$ Emma S. McBryde, ${ }^{4}$ Archie C.A. Clements ${ }^{1}$ \\ ${ }^{1}$ Research School of Population Health, College of Health and Medicine, The Australian National \\ University, Canberra, Australia; ${ }^{2}$ Institute of Public Health, College of Medicine and Health Sciences, \\ University of Gondar, Gondar, Ethiopia; ${ }^{3}$ Department of Public Health Sciences, Karolinska Institutet, \\ Stockholm, Sweden; ${ }^{4}$ Australian Institute of Tropical Health and Medicine, James Cook University, \\ Townsville, Australia
}

\begin{abstract}
The burden of tuberculosis (TB) in children reflects continuing and recent transmission within a population. This study aimed to identify spatiotemporal and socio-climatic factors associated with paediatric TB in north-western Ethiopia. Multivariate Poisson regression models were computed using a Bayesian
\end{abstract}

Correspondence: Kefyalew Addis Alene, Research School of Population Health, College of Health and Medicine, The Australian National University, 62 mills road 2601, Acton, Canberra, Australia. Tel: +61404705064 .

E-mail: Kefyalew.alene@anu.edu.au

Key words: Tuberculosis; Transmission; Paediatric; Epidemiology; Ethiopia.

Contributions: KAA conceived, designed and prepared the draft manuscript. KV improved the drafted manuscript. KV, EM, AC advised the overall data analysis and the development of the manuscript. All the authors were involved with critical revision of the manuscript, and approved the final version.

Conflict of interest: the authors declare no potential conflict of interest.

Funding: external funding was not received for this study.

Ethical statement: ethical clearance was obtained from the Australian National University Human Research Ethics Committee (protocol number 2016/219). A letter of cooperation was obtained from the University of Gondar, Ethiopia and the North Gondar Health Department provided permission to access the HMIS data. As this study used secondary data, informed consent was not obtained from the study participants.

Received for publication: 7 April 2017.

Revision received: 26 October 2017.

Accepted for publication: 1 November 2017

CC Copyright K.A. Alene et al., 2017

Licensee PAGEPress, Italy

Geospatial Health 2017; 12:575

doi:10.4081/gh.2017.575

This article is distributed under the terms of the Creative Commons Attribution Noncommercial License (CC BY-NC 4.0) which permits any noncommercial use, distribution, and reproduction in any medium, provided the original author(s) and source are credited. framework. Estimates of parameters were generated using Markov chain Monte Carlo simulation. A total of 2,240 children aged under 15 years diagnosed with TB during the years 20132016 were included in the analysis. The annual TB incidence rates were 44 and 28 per 100,000 children, for children aged under 15 and 5 years, respectively. Spatial clustering of TB was observed in the border area of north-western Ethiopia. The spatio-temporal transmission of childhood TB was found to be associated with district level socio-climatic factors such as urbanisation [relative risk (RR): $1.8 ; 95 \%$ credible interval $(\mathrm{CrI}): 1.2,2.6]$, lower educational status (RR: $1.5 ; 95 \% \mathrm{CrI}: 1.0,2.1$ ), a high percentage of internal migration (RR: 1.3 ; 95\% CrI: 1.0, 1.6), high temperature (RR: 1.3 ; 95\% CrI: $1.0,1.7$ ) and high rainfall (RR: 1.5 ; 95\% CrI: $1.1,2.0$ ). We conclude that interventions targeting hotspot districts with a high proportion of childhood TB are important to reduce TB transmission in northwest Ethiopia.

\section{Introduction}

Tuberculosis (TB) is an infectious disease caused by bacteria of the Mycobacterium tuberculosis complex transmitted via airborne spread of droplet nuclei produced by patients with infectious pulmonary or laryngeal TB (Sia and Wieland, 2011). The worldwide distribution of the disease, which varies by time period and place (Tiwari et al., 2006; Touray et al., 2010; Li et al., 2013; Nana et al., 2014; Dangisso et al., 2015b; Woldeyohannes and Abera, 2015), is partly determined by ecological level factors such as socio-economic (Leung et al., 2004; Nana et al., 2014), demographic (Feske et al., 2011), climatic (Li et al., 2014) and other environmental factors (Sun et al., 2015).

Young children, particularly those aged under 15 years of age, are a vulnerable group for TB infection and disease (Perez-Velez and Marais, 2012). Due to the long latency period in infected adults, and the uncertainty around when and where exposure occurred, it is difficult to infer ongoing transmission in communities from the incidence of TB in adults. Because children tend to progress rapidly to active TB following initial infection, the incidence of TB in children is a very good indicator of continuing and recent TB transmission within a population (Middelkoop et al., 2008; Myers et al., 2006; Newton et al., 2008; Shingadia and Novelli, 2003; WHO, 2013). Children usually acquire TB infection when they are exposed to an infectious adult in their close environment, either in the household or in the community (Ferrarini et al., 2016; Triasih et al., 2015). The rate at which latent $\mathrm{TB}$ infection progresses to active disease varies by age 
group and immune status. In the first year after initial infection, the risk of progression of latent TB infection to active TB disease in immunocompetent children aged less than 1 year is approximately $60 \%$, for children age less than 5 years about $10 \%$, and for children aged less than 15 years approximately 20\% (Marais et al., 2004a, 2004b, 2006; Newton et al., 2008).

The transmission of TB and subsequent development of active TB disease is determined by ecological and individual-level factors (Escombe et al., 2008; Loudon and Spohn, 1969). Individuallevel clinical, behavioural, socio-economic and demographic risk factors have been well described (Coker et al., 2006; Lienhardt Christina et al., 2003b, 2005; Nava-Aguilera et al., 2009). However, information about community-level and ecological factors is also important when implementing public health interventions based on the local context. Previous studies have described ecological-level socio-economic, demographic and climatic factors associated with TB transmission (Myers et al., 2006; Rao et al., 2016), however those studies have been conducted in highincome settings with low rates of TB transmission, or they have used both adult and childhood cases of TB that makes it impossible to differentiate whether the cases were due to primary infection, reinfection or reactivation of an old one (Chiang and Riley, 2005; Cohen et al., 2007; Lambert et al., 2003). In addition, there have been few spatial analyses of TB in endemic countries (Alene et al., 2017; Jia et al., 2008; Touray et al., 2010; Wang et al., 2012). Such analyses can help identify clusters, or transmission hotspots. This information is useful when targeting surveillance activities and public health interventions (Kolifarhood et al., 2015; Souza et al., 2007; Tsai, 2011). Therefore, the aim of this study was to investigate the spatio-temporal patterns of paediatric TB and to identify socio-economic and climatic factors associated with childhood TB incidence leading to a better understand the factors driving TB transmission in high-burden settings.

\section{Materials and Methods}

\section{Study setting}

The study was conducted in North Gondar Zone, Ethiopia. This is the largest zone in the Amhara region located in north-western Ethiopia, with an estimated mean elevation of 1,422 metres above the mean sea level (Figure 1). This region has four distinct seasons: summer (rainy season) from June to August, autumn (harvest season) from September to November, winter (dry season with frost in the morning) from December to February, and spring (the hottest season) from March to May. North-western Ethiopia contains 23 administrative districts and borders Sudan in the West and Eritrea in the North. Three of the districts were excluded from the study due to unavailability of data.

In Ethiopia, the district is the smallest administrative unit where both routine disease surveillance and national census data can be linked and geo-referenced. The average population size of a district in north-western Ethiopia is 146,481 people (CSA, 2007). According to the Ethiopian census report, there were 1.28 million children under 15 years of age and 430,844 children under 5 years of age in this region in 2007 (CSA, 2007).

\section{Study participants}

All new cases of TB in children aged under 15 years who were reported to the surveillance system for the period July 2013 to June 2016 were included in the study. Separate but similar models were constructed for children aged under 5 years and under 15 years since as TB in the former category mainly represents household transmission, whereas $\mathrm{TB}$ in the latter group represents both household and community transmission (Swaminathan and Rekha,

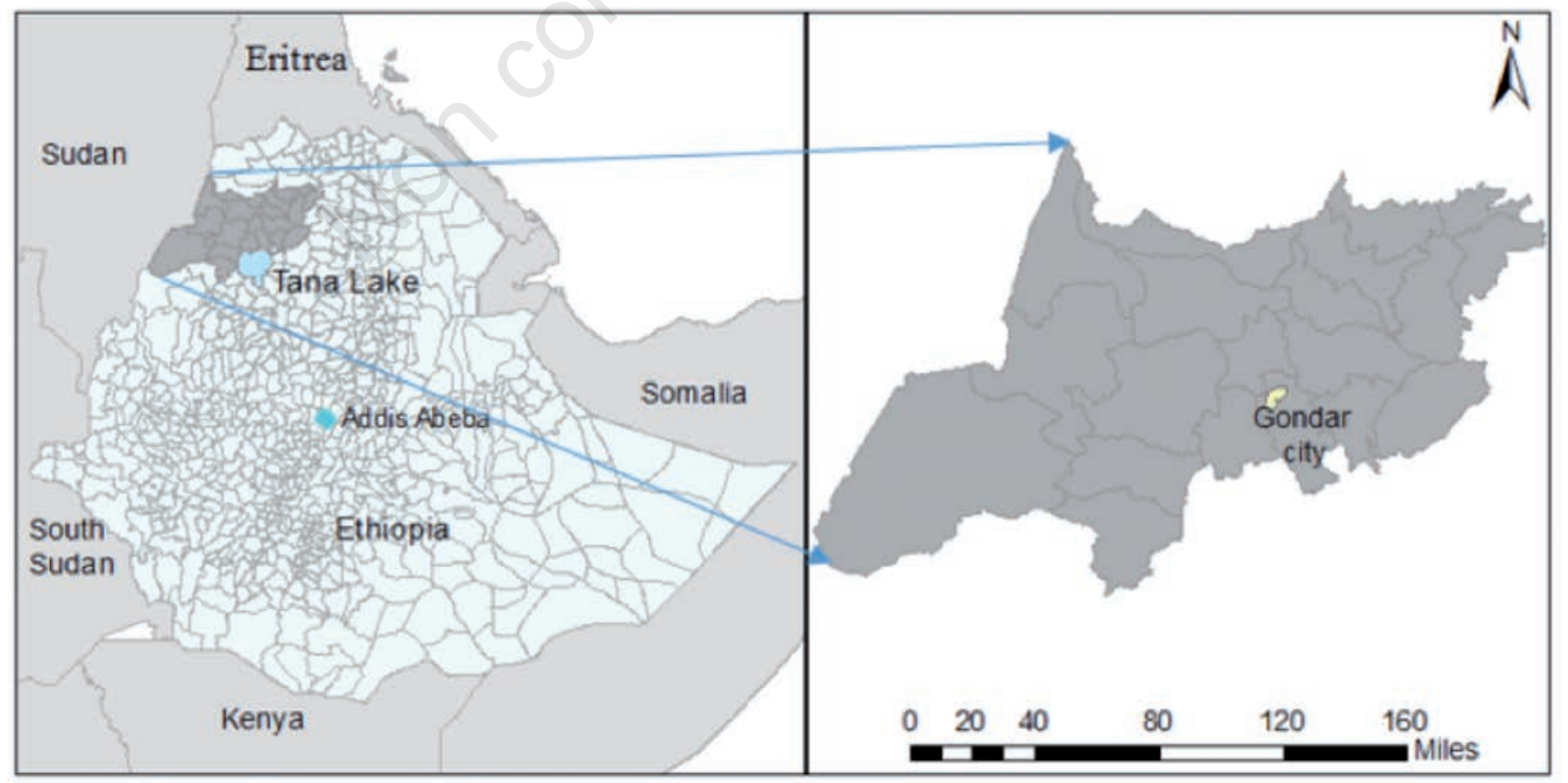

Figure 1. The geographical location of the study area (the study was conducted in the shaded part of Ethiopia, i.e., north-western Ethiopia). 
2010). In the analysis, the group under-15 included the group under-5.

\section{Data collection and management}

TB data for 20 districts were obtained from the Tuberculosis Control and Prevention Office, North Gondar Health Department. In Ethiopia, children with TB are usually detected either passively, i.e. they present to a health care service with signs and symptoms suggestive of $\mathrm{TB}$, or actively as a result of contact tracing of infectious adults. TB is diagnosed based on a clinical examination, a medical history and if feasible through bacteriological confirmation (MOH, 2012). Both clinically and bacteriologically confirmed cases of TB are notified to the surveillance system on a quarterly basis and data are stored in an electronic health management information system (HMIS). Since the laboratory diagnosis of TB in children is generally difficult due to difficulties in obtaining sputum for smear microscopy, and the unavailability of chest radiography, the majority of TB diagnoses in children are based on clinical examination and medical history ( $\mathrm{MOH}, 2008)$. In this study, we included both clinically and bacteriologically confirmed new cases of TB in children aged under fifteen years.

District-level demographic variables (i.e., residence, education, illiteracy rate and internal migration); socioeconomic factors (i.e., economic inactivity and unemployment rate); housing conditions (i.e., average number of families in a house); indoor air pollution (i.e., traditional kitchen inside the house with charcoal, firewood and dung used for cooking) were obtained from the 2007 Ethiopian census report (CSA, 2007) (Table 1). Monthly climatic data, including minimum, maximum and mean temperatures as well as mean rainfall were obtained from the global climate website, Worldclim (http://worldclim.org/version2). Since TB data were collected quarterly, the monthly climatic data were also aggregated into quarters. The population density of each district was calculated as the total population living in the district divided by the area of the district in $\mathrm{km}^{2}$.

The incubation period of TB in children (i.e., the period from initial infection to clinical manifestation of signs and symptoms) can vary from weeks to months (Esposito et al., 2013,
Swaminathan and Rekha, 2010) and the delay in seeking health care can vary according to the health seeking behaviour of the parents (Gelaw et al., 2014). The lag time between climatic exposure and reporting of active TB disease was assessed by performing a preliminary analysis. In this preliminary analysis, the association between the incidence of TB and minimum temperature, maximum temperature, mean temperature and rainfall were determined by cross-correlation plots using a moving average filter to decompose time trends. The relationship between TB and temperature was better explained by mean temperature rather than minimum and maximum temperature. Therefore, to avoid the effects of multicollinearity in meteorological variables, minimum and maximum temperature were excluded from the models, and only the mean temperature, with a six-month lag, was included.

\section{Data analysis}

\section{Tuberculosis incidence rate}

The cumulative incidence rate of childhood TB was calculated by dividing the total number of new paediatric TB cases between 2013 and 2016, by the population of the same age group in the corresponding districts, multiplied by 100,000 to obtain a rate per 100,000 population. Since the independent variables, including population density, average number of families in a house, mean temperature and mean rainfall have different units and scales of measurement that would have produced unknown threshold effects, we calculated the arithmetic mean and standard deviation (SD) for each of the district-level independent variables and standardised them to a $\mathrm{z}$-scale on the basis of their mean and SD, i.e. (X-mean)/SD. This method also helps with identifiability in the estimation of the posterior distribution of the coefficients. A similar technique has been used in previous research to address this problem (Myers et al., 2006).

\section{Spatial analysis}

TB data were geo-referenced and linked to the district level socio-economic, demographic and climatic data using geographical information system (GIS) using ArcGIS software (ESRI, Redlands, CA, USA). Spatial clustering of paediatric TB was

Table 1. Descriptive characteristics of twenty census districts in north-western Ethiopia.

\begin{tabular}{|c|c|c|c|c|}
\hline Variable & Definition & Mean & SD & Range \\
\hline Internal migration (\%) & Percentage of population that had immigrated to a district within the last five years of the census & 13.4 & 15.4 & 3.3-57.1 \\
\hline No schooling (\%) & Percentage of people 5 years and older who never attended school & 70.5 & 7.5 & $50.0-80.0$ \\
\hline Urban residence (\%) & Percentage of urban residence in the districts & 17.0 & 16.2 & $0-63.3$ \\
\hline Unemployment (\%) & Percentage of unemployed people aged 10 years and older in the labour force & 3.0 & 3.8 & $0.3-16.5$ \\
\hline Non-active economically (\%) & $\begin{array}{l}\text { Percentage of population } 10 \text { years and older neither engaged in nor available for production } \\
\text { of economic goods and services }\end{array}$ & 32.1 & 10.8 & 14.1-48.6 \\
\hline Household crowding (n) & Average number of families in a house & 1.0 & 0.01 & $1.02-1.05$ \\
\hline Population density (n) & Number of people per km² & 102.9 & 77.6 & 11.9-349.8 \\
\hline Traditional cooking inside house (\%) & Percentage of the population using a traditional kitchen inside the house & 11.5 & 6.0 & $4.3-27.5$ \\
\hline Burning charcoal for heating food (\%) & Percentage of the population using charcoal for cooking & 17.9 & 15.8 & 2.9-57.1 \\
\hline Burning wood use for heating food (\%) & Percentage of the population using firewood for cooking & 88.2 & 4.8 & 76.0-96.3 \\
\hline Burning dung for heating food (\%) & Percentage of the population using dung for cooking & 64.3 & 30.0 & 4.4-95.3 \\
\hline Temperature $\left({ }^{\circ} \mathrm{C}\right)$ & Monthly average environmental mean air temperature & 21.1 & 5.2 & $7.2-29.9$ \\
\hline$\underline{\text { Rainfall }(\mathrm{mm})}$ & Monthly average mean rainfall & 82.0 & 92.2 & $0-316.6$ \\
\hline
\end{tabular}

SD, standard deviation. 
assessed on a global scale using Moran's I statistic to gauge the presence, strength and direction of spatial autocorrelation over the whole study area and to test the assumption of spatial independence when implementing spatial pattern analysis (Appendix 1). Spatial clustering was also assessed at the local scale using the Anselin Local Moran's I statistic, and the Getis-Ord statistic (Anselin, 1995; Getis and Ord, 1992).

\section{Spatiotemporal analysis}

Since the number of children with TB in each district was a count variable, we assumed that it followed a Poisson distribution. We accounted for extra-Poisson variation by using covariates and random effects. Four different spatiotemporal Poisson regression models were constructed in a Bayesian framework, using the WinBUGS software, version 1.4 (Medical Research Council Biostatistics Unit, Cambridge, UK). The models were constructed with and without covariates to ascertain the ability of socio-climatic covariates to describe the spatiotemporal dependency of the data. The following models were used: I) without covariates; II) with covariates and unstructured random effects; III) with covariates and spatially structured (i.e., correlated) random effects; and IV) with covariates and spatially structured and unstructured random effects.

Model 4, which includes all the components in the preceding models, was constructed as follows:

$Y_{i, j} \sim \operatorname{dPoissson}\left(\mu_{i j}\right)$

where $Y_{i, j}$, is the observed number of paediatric TB cases at the district level $i$ and quarter $j$, was assumed to follow a Poisson distribution with mean $\mu_{i j}$; The $\log$ of the mean value was modelled as:

$\log \left(\mu_{i j}\right)=\log \left(E_{i j}\right)+\alpha+\beta_{k} X_{i j k}+\gamma t+U_{i}+V_{i}$

where $E_{i j}$ is the expected number of paediatric TB cases in district $i$ and quarter $j, \alpha$ the intercept, $\beta_{k}$ the coefficient for covariate $X_{k} \gamma$ the temporal trend in the outcome variable, t the 16 quarters of the annual period 2013-2016, Ui unstructured random effects and $V_{i}$ spatially structured random effects.

The spatially structured random effects were modelled using a conditional autoregressive (CAR) structure (Besag et al., 1991). The neighbourhood structure for the modelling of spatial correlation was based on the queen definition, whereby two areas are considered neighbours if they share a common boundary or vertex. Prior probability distributions for the coefficients $\beta$ were assumed to have normal distributions with a mean $=0$ and a precision (i.e., inverse of variance $)=1 \times 10^{-6}$. For the intercept $\alpha$, flat prior distributions were used (i.e., a non-informative, improper prior with bounds $-\infty$ and $+\infty$ ). The prior for the precision of the unstructured and spatially structured random effects were assigned a non-informative gamma distribution with shape and scale parameters equalling 0.001 .

The posterior parameters were estimated using a Bayesian Markov Chain Monte Carlo (MCMC) simulation. Convergence of the models was determined by visual inspection of posterior kernel densities and history plots. The model was run for 300,000 iterations and convergence occurred within the first 100,000 iterations. The models with best fit were selected on the basis of deviance information criteria (DIC) value, whereby a model with a lower DIC value was considered to be a better-fitting model. Details of the model construction are presented in Appendix 2.

\section{Results}

A total of 2,240 new cases of paediatric TB in children under 15 were reported to the zonal health department surveillance system through the HMIS from June 2013 to June 2016. Twenty-two percent (484) of the children were under 5 years, and 53\% $(1,180)$ were male. The largest proportion of cases was from Gondar Town $(17 \%, 391)$ and Metema District $(11 \%, 250)$. The annual incidence rate for new cases of paediatric TB was 44 per 100,000 children for children under 15 years and 28 per 100,000 children, for children under 5 . The spatial distribution of TB for both age groups of children in north-western Ethiopia is presented in Figure 2. The TB incidence rate ranged from 13 to 317 per 100,000 children for children under 15 years and from 5 to 198 per 100,000 children for children under 5 . The highest TB incidence rates were observed in West Armacho District (317 and 198 per 100,000 children, for children under 15 and 5 years, respectively) and Metema District (147 and 119 per 100,000 children, for children under 15 and 5 years, respectively) (Figure 2).

Data from the Ethiopian national census report indicated that the mean proportion of the population who were immigrants within the last five years of the census was $13.4 \%$ (SD: $15.4 \%$ ). The majority of the population $(70.5 \%$, SD: 7.5$)$ were generally illiterate and $17.0 \%$ (SD: 7.5 ) lived in urban areas. The mean temperature and rainfall for the study area were $21^{\circ} \mathrm{C}$ (SD: 5.2) and $82 \mathrm{~mm}$ (SD: 92.2), respectively (Table 1 ).

\section{Temporal trends of paediatric tuberculosis}

The number of paediatric TB cases peaked in the $4^{\text {th }}$ quarter, during the spring season, in all years (Figure 3). The number of cases was highest in 2013 and declined over the study period (Relative Risk (RR): 0.96; 95\% CI: 0.95, 0.97). Trends in mean temperature and mean rainfall reflected trends in the number of children diagnosed with TB and were confirmed by the cross-correlation graph (Figure 3). The final model showed that the 6-month lag temperature (RR: 1.3 ; 95\% CrI: $1.0-1.7$ ) and rainfall (RR: 1.5 ; 95\% CrI: 1.1-1.9) were significantly associated with TB in children less than 15 years, but not in children under 5 (Table 2).

\section{Spatio-temporal patterns of paediatric tuberculosis}

Paediatric TB was clustered in north-western Ethiopia (Global Moran's $I=0.14 ; \mathrm{P}=0.007)$. A high-high cluster of cases was observed in Metema and West Armacho Districts, and a hotspot for new cases of TB for both age groups was observed in Metema District (Figure 4). When the socio-climatic variables were incorporated into the model, spatial clustering was not apparent in the residuals (Global Moran's $I=-0.18 ; \mathrm{P}=0.17$ ), indicating that the covariates could explain the spatial clustering in childhood TB counts. Based on the lowest DIC value, the model that contained covariates with an unstructured random effect was the best-fitting model for both age groups of children (Table 2).

Table 2 shows the fitted model for both age groups. In the bestfitting model for children aged under 15, lower (illiterate) educational status (RR: 1.5; 95\% CrI: 1.0, 2.1), urbanisation (RR: 1.8; 95\% CrI: 1.2, 2.6), high temperature (RR: 1.3; 95\% CrI: 1.0, 1.7) and high rainfall (RR: $1.5 ; 95 \%$ CrI: $1.1,2.0)$ were significantly associated with paediatric TB. When the model was restricted to children aged under 5, female sex (RR: 1.6; 95\% CrI: 1.3, 1.9), urbanisation (RR: 1.6; 95\% CrI: 1.1, 2.2) and a high proportion of internal migrants (RR: 1.3 ; 95\% CrI: $1.0,1.6)$ were significantly associated with paediatric TB (Table 2). 


\section{Discussion}

The results presented fully explained observed spatial clustering of paediatric TB in the study area. The temporal trend of TB decreased over the study period, and the incidence was shown to have seasonal variation, with more TB observed in the spring. The decline of TB incidence in north-western Ethiopia over the study period might be due to improvements in TB treatment outcomes and TB care overall (Datiko and Lindtjørn, 2009; Dangisso et al., 2015a). According to the World Health Organization (WHO), the TB treatment success rate for new cases increased in Ethiopia from $77 \%$ in 2010 to $89 \%$ in 2015 (WHO, 2012, 2016). This could be also associated with expansions of directly observed therapy (DOT) and other prevention programmes ( $\mathrm{MOH}, 2008$; Dangisso et al., 2015a). The national TB programme report from the Ministry of Health (MOH) showed that the number of hospitals and health centres providing DOT services in the country increased by more than $62 \%$ between 2010 and 2013 (MOH, 2013).

The observed seasonal pattern, with a peak observed from March to May (i.e., spring) could be a consequence of high rates of TB transmission during the winter season resulting in active TB developing several weeks or months later (Vynnycky and Fine, 2000; Marais et al., 2004a). This is consistent with previous studies where high rates of TB transmission have occurred during the winter season (Thorpe et al., 2004; Fares, 2011; Willis et al., 2012), which could be due to seasonal variations in food availability and food intake (Roba et al., 2015; Hirvonen et al., 2016), indoor overcrowding (Parrinello et al., 2012) and low exposure to sunlight and its subsequent impact on vitamin D levels (Webb et al., 1988; Sherman et al., 1990; Nnoaham and Clarke, 2008). In addition, during the winter season there are high levels of rainfall and humidity, which may decrease airflow and favour TB transmission. This is supported by our results, whereby high rainfall recorded was associated with increased incidence of TB (Figure 3).

The observed seasonal pattern of TB could be related to migration patterns. In our study, the internal-migrant proportion of the population was associated with TB transmission. The majority of internal migrants are seasonal workers who come from different parts of the country and who are employed in the agricultural sector (Asfaw et al., 2010). These people live, work and eat together in overcrowded living conditions, which may further facilitate TB transmission. Our study identified also urbanisation as a TB risk factor, which is supported by previous studies reporting that TB incidence is associated with urban residence, poor quality housing with overcrowding, lack of water and sanitation (Barnes et al., 2011; Prasad et al., 2016). Indeed, environmental factors that facilitate TB transmission may be more common in urban settings (Lienhardt Christian et al., 2003a, 2003b; Narasimhan et al., 2013).

Furthermore, socioeconomic status has been associated with TB. In districts where a high proportion of the population was illiterate, childhood TB rates were found to be high. This could be due to the fact that lower educational status may lead to a poorer understanding of the transmission of the disease and self-protective measures. It may also be associated with poor living conditions, including household overcrowding and other issues, such as poor access to healthcare. This may suggest that higher educational levels at the community level may reduce TB transmission and incidence. Wealth and levels of educational attainment have been associated with TB across many settings (Harling et al., 2008; Suk et al., 2009).

The present study is the first published study on the spatio-temporal distribution of paediatric TB in Ethiopia. The study included several

Table 2. Socio-climatic factors associated with tuberculosis in children in north-western Ethiopia in the period 2013-2016.

\begin{tabular}{|c|c|c|c|c|c|c|}
\hline \multirow[t]{2}{*}{ District-level variable } & \multicolumn{3}{|c|}{ Children under 15 years } & \multicolumn{3}{|c|}{ Children under 5 years } \\
\hline & $\begin{array}{l}\text { Model II\#: } \\
\text { Unstructured } \\
\text { RR ( } 95 \% \text { CrI) }\end{array}$ & $\begin{array}{l}\text { Model IIIs: } \\
\text { Structured } \\
\text { RR }(95 \% \text { CrI) }\end{array}$ & $\begin{array}{l}\text { Model IV^: } \\
\text { Unstructured and } \\
\text { structured } \\
\text { RR }(95 \% \mathrm{Crl})\end{array}$ & $\begin{array}{l}\text { Model II\#: } \\
\text { Unstructured } \\
\text { RR ( } 95 \% \text { CrI) }\end{array}$ & $\begin{array}{l}\text { Model IIIs: } \\
\text { Structured } \\
\text { RR }(95 \% \mathrm{CrI})\end{array}$ & $\begin{array}{c}\text { Model IV^: } \\
\text { Unstructured and } \\
\text { structured } \\
\text { RR }(95 \% \mathrm{Crl})\end{array}$ \\
\hline Female & $1.08(0.99,1.17)$ & $1.08(0.99,1.17)$ & $1.08(0.99,1.17)$ & $1.60(1.33,1.92)$ & $1.60(1.33,1.92)$ & $1.60(1.33,1.92)$ \\
\hline Education status illiterate (\%) & $1.47(1.02,2.06)$ & $1.29(0.86,1.84)$ & $1.41(0.95,2.02)$ & $1.19(0.85,1.66)$ & $1.09(0.77,1.52)$ & $1.16(0.81,1.62)$ \\
\hline New internal migrant (\%) & $1.09(0.841 .39)$ & $1.18(0.87,1.55)$ & $1.13(0.85,1.46)$ & $1.29(1.01,1.60)$ & $1.40(1.07,1.77)$ & $1.32(1.03,1.67)$ \\
\hline Use of firewood for cooking (\%) & $1.05(0.841 .29)$ & $1.05(0.76,1.39)$ & $1.04(0.80,1.32)$ & $1.03(0.84,1.25)$ & $1.06(0.81,1.38)$ & $1.04(0.82,1.30)$ \\
\hline Urban population (\%) & $1.85(1.25,2.62)$ & $1.59(1.03,2.31)$ & $1.76(1.15,2.58)$ & $1.58(1.14,2.22)$ & $1.40(0.97,1.97)$ & $1.53(1.06,2.16)$ \\
\hline Autumn (Sep-Nov) & $0.74(0.61,0.88)$ & $0.72(0.58,0.89)$ & $0.73(0.59,0.88)$ & $0.86(0.60,1.18)$ & $0.88(0.60,1.23)$ & $0.86(0.60,1.20)$ \\
\hline Summer (Dec-Feb) & $0.46(0.20,0.91)$ & $0.42(0.18,0.84)$ & $0.44(0.19,0.90)$ & $0.41(0.06,1.41)$ & $0.38(0.05,1.35)$ & $0.40(0.06,1.43)$ \\
\hline Spring (Mar-May) & $1.14(0.91,1.41)$ & $1.11(0.88,1.38)$ & $1.13(0.90,1.40)$ & $0.90(0.55,1.40)$ & $0.88(0.53,1.38)$ & $0.89(0.53,1.40)$ \\
\hline Temperature $\left({ }^{\circ} \mathrm{C}\right)$ & $1.34(1.04,1.73)$ & $1.37(0.99,1.88)$ & $1.36(1.02,1.82)$ & $1.20(0.91,1.59)$ & $1.12(0.81,1.52)$ & $1.19(0.88,1.59)$ \\
\hline Rainfall (mm) & $1.50(1.11,1.98)$ & $1.56(1.15,2.08)$ & $1.53(1.12,2.03)$ & $1.68(0.89,2.88)$ & $1.75(0.90,3.08)$ & $1.72(0.89,3.03)$ \\
\hline Temporal pattern (by quarter) & $0.96(0.95,0.97)$ & $0.96(0.95,0.97)$ & $0.96(0.95,0.97)$ & $0.94(0.92,0.96)$ & $0.94(0.92,0.96)$ & $0.94(0.92,0.96)$ \\
\hline Constant & $0.29(-0.08,0.67)$ & $0.35(0.01,0.69)$ & $0.31(-0.07,0.67)$ & $0.30(-0.32,0.92)$ & $0.35(-0.27,0.97)$ & $0.32(-0.32,0.96)$ \\
\hline Variance (unstructured) & $7.05(2.64,14.0)$ & - & $58.14(2.99,558.0)$ & $16.69(3.6,53.9)$ & - & $65.98(3.91,552.0)$ \\
\hline Variance (spatially structured) & - & $1.62(0.60,3.25)$ & $127.40(0.92,1056.0)$ & - & $7.33(0.8,21.6)$ & $176.70(1.5,1283.0)$ \\
\hline DIC & 2839.45 & 2841.81 & 2842.42 & 1379.47 & 1383.14 & 1380.80 \\
\hline DIC (without covariate) ${ }^{\circ}$ & 2848.30 & - & - & 1383.74 & - & - \\
\hline
\end{tabular}

DIC, deviance information criterion; RR, relative risk; CrI, credible interval. ${ }^{\circ}$ Value obtained from Model I (i.e. the model without covariate); ${ }^{\circledR}$ model with covariates and unstructured random effects (i.e. fixed effects

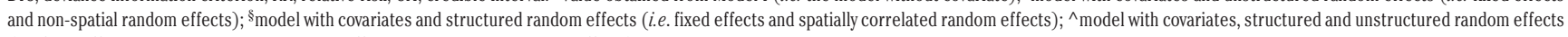
(i.e. fixed effects, spatially correlated random effects and non-spatial random effects). 


\section{Article}

A

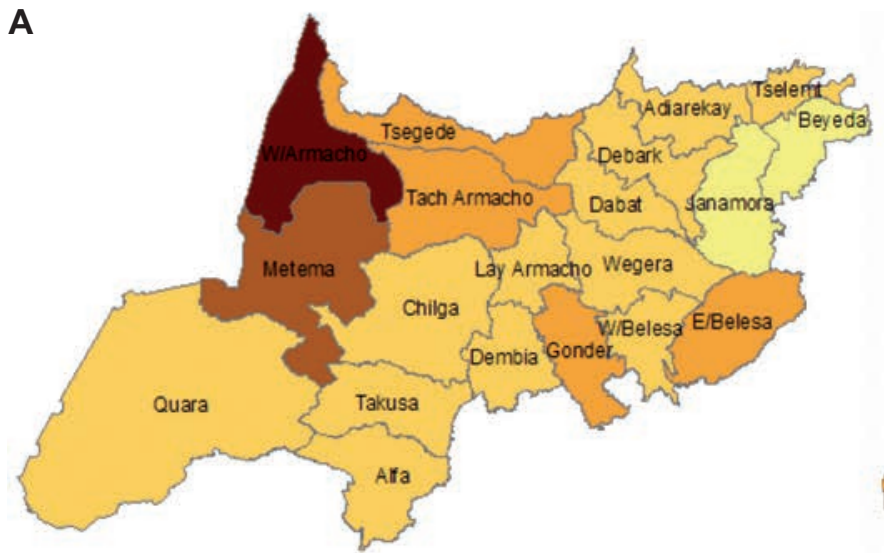

$12.7 \cdot 16.3$

$16.4-43.3$

$43.4-91.1$

91.2 - 146.9

$147.0 \cdot 317.0$
B

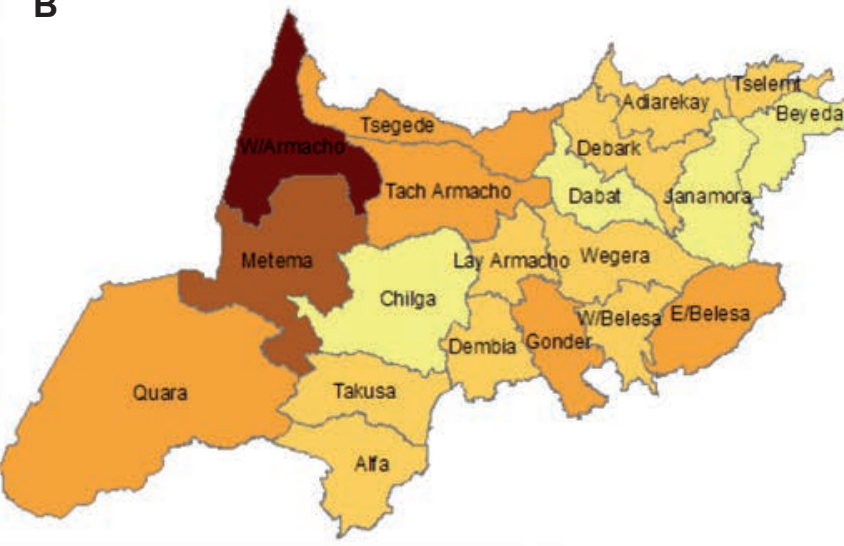

$5.4 \cdot 12.9$

$13.0 \cdot 24.2$

$24.3 \cdot 49.3$

$49.4-119.2$

119.3 - 198.1

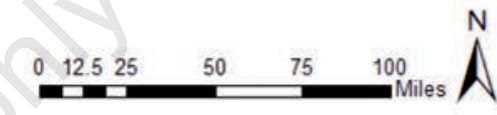

Figure 2. Paediatric tuberculosis annual incidence rates per 100,000 children in twenty districts of north-western Ethiopia: A) for children under fifteen years; B) for children under five years.
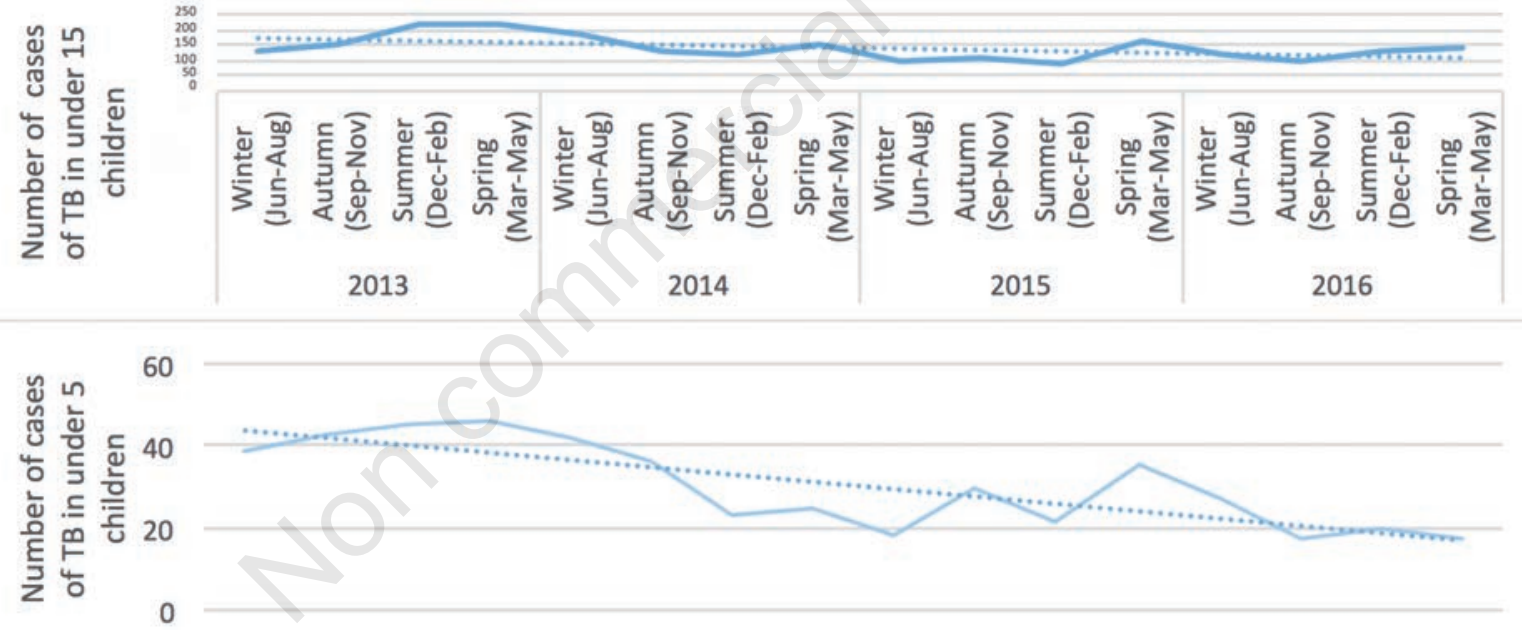

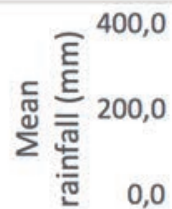
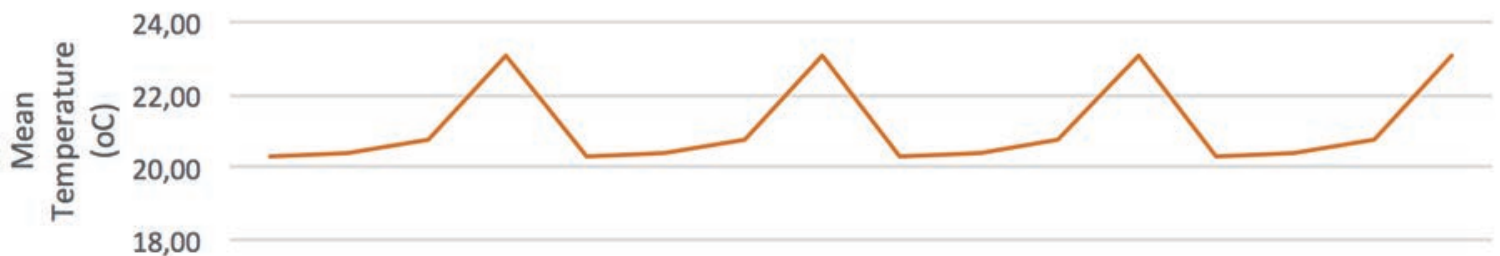

Figure 3. Tuberculosis diagnoses in children under fifteen years and in children under five years compared to temperature and rainfall in north-western Ethiopia by quarter over the period 2013-2016. 
ecological variables that were associated with rates of TB, but all environmental variables plausibly associated with TB were not included. For instance, temperature and rainfall are not the only climatic factors that may be associated with TB transmission, other important meteorological variables such as hours of sunshine, wind speed and atmospheric pressure may also be associated (Rao et al., 2016). However, since north-western Ethiopia is located in a tropical region, some climatic factors, such as hours of exposure to sunshine, are relatively homogenous in the study area. Additionally, it should be acknowledged that TB transmission is multi-factorial and heavily influenced by socio-economic factors, many of which we did not examine.

Given that this was an area-level analysis, it is important to acknowledge the ecological fallacy, whereby associations at one level of aggregation cannot be assumed to hold true at other levels, including for individual people in the study area. Under-detection and under reporting of paediatric TB are a potential limitation of the study, and the exact burden of TB among children in northwestern Ethiopia is not be known. Finally, we have not incorporated some other important clinical risk factors into the analysis such as HIV infection, a potent risk factor for TB.

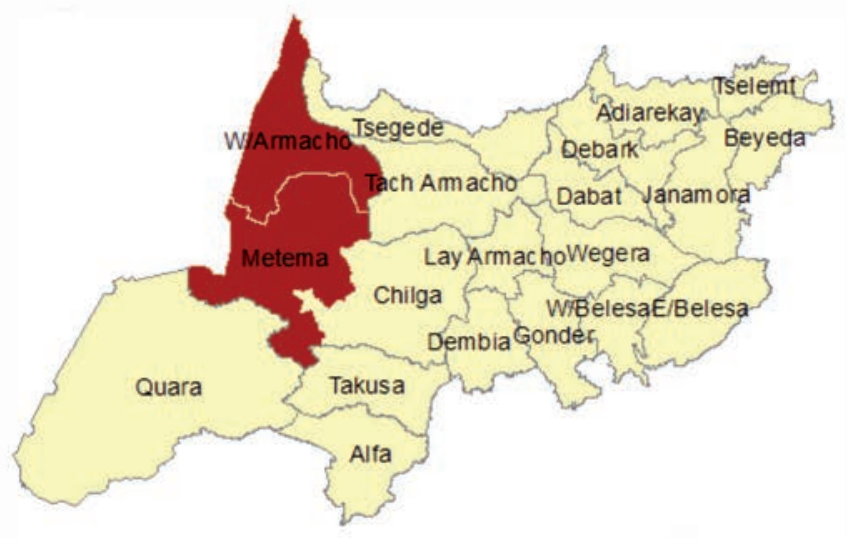

Cluster of TB in under 15 children
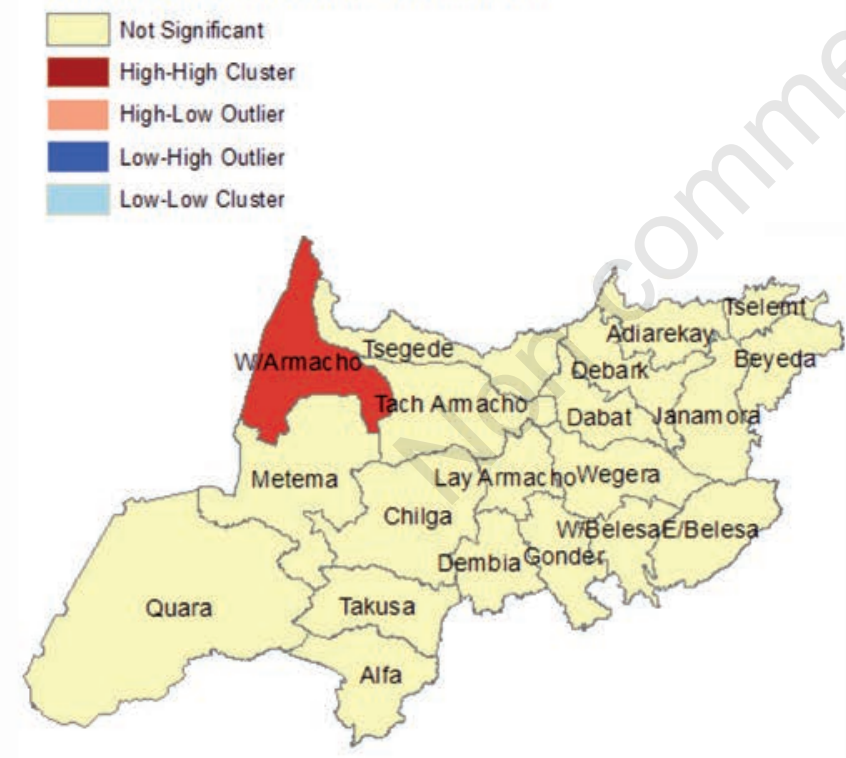

Hot spot for under 15 children

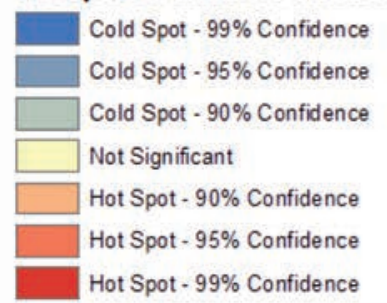

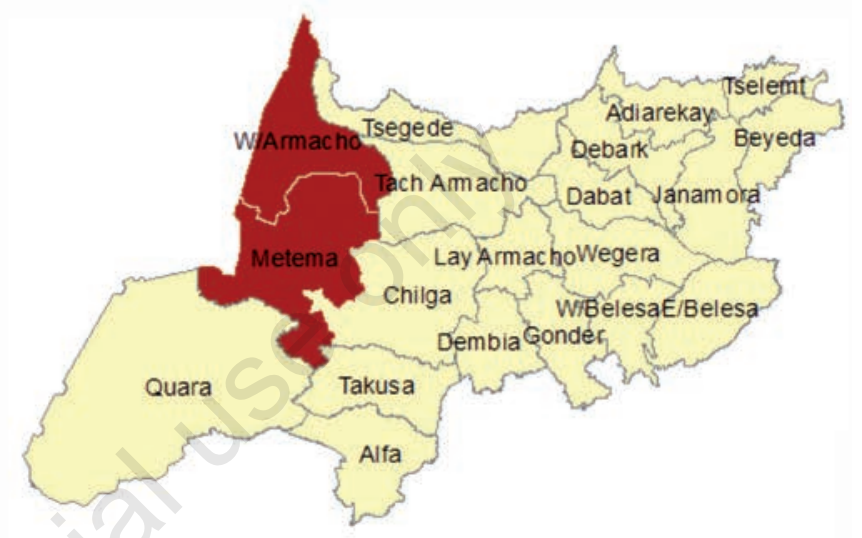

\section{Cluster of TB in under 5 children}
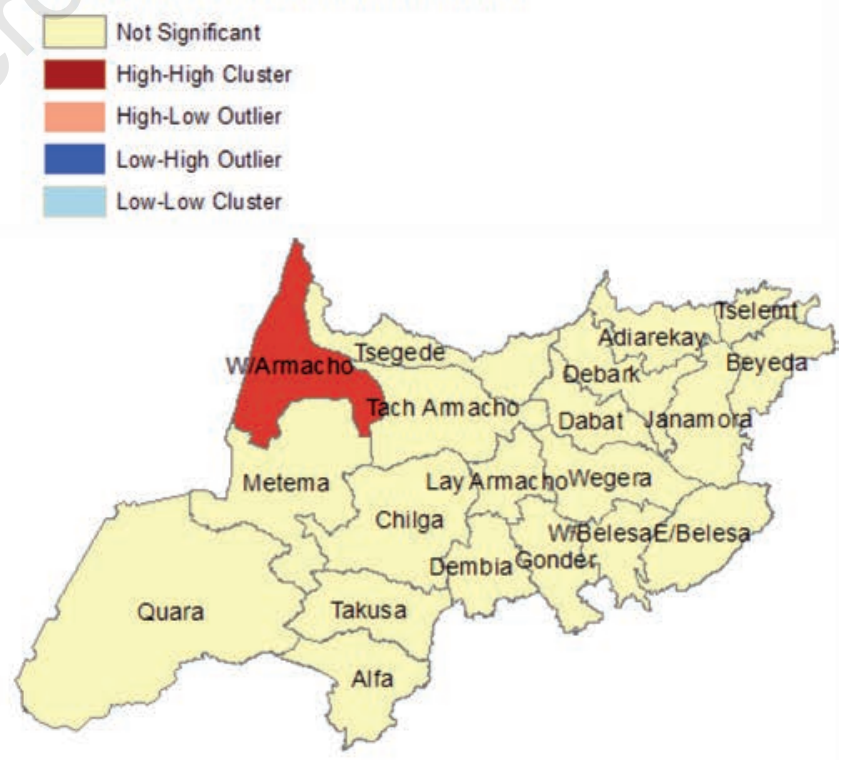

Hot spot for under 5 children

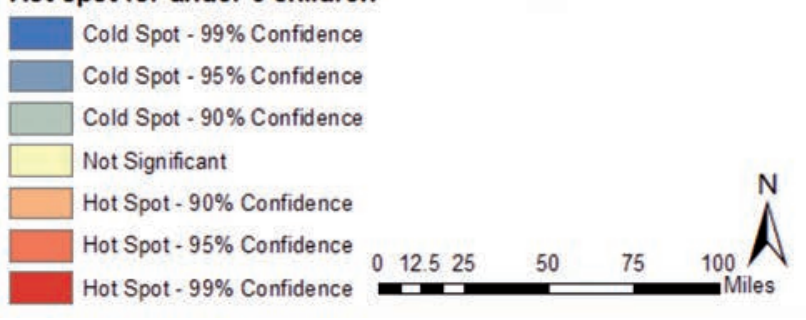

Figure 4. Spatial clusters tuberculosis incidence rate and hot spots for children in north-western Ethiopia in the period $2013-2016$. 


\section{Conclusions}

We found that paediatric TB was spatiotemporally clustered in north-western Ethiopia and that clustering was associated with several socio-climatic factors, including urbanisation, internal migration, educational status, rainfall, and temperature. The identification of paediatric TB clustering can help to identify TB transmission hotspots. Using this information, decision-makers may want to implement focused interventions for the control and prevention of TB in high-transmission districts.

\section{References}

Alene KA, Viney K, McBryde ES, Clements AC, 2017. Spatial patterns of multidrug resistant tuberculosis and relationships to socio-economic, demographic and household factors in northwest Ethiopia. PLoS One 12:e0171800.

Anselin L, 1995. Local indicators of spatial association-lisa. Geogr Anal 27:93-115.

Asfaw W, Tolossa D, Zeleke G, 2010. Causes and impacts of seasonal migration on rural livelihoods: Case studies from Amhara region in Ethiopia. Norwegian J Geogr 64:58-70.

Barnes I, Duda A, Pybus OG, Thomas MG, 2011. Ancient urbanization predicts genetic resistance to tuberculosis. Evolution 65:842-8.

Besag J, York J, Mollie A, 1991. Bayesian image restoration with two applications in spatial statistics. Ann Inst Stat Mat 43:1-59.

Chiang C-Y, Riley LW, 2005. Exogenous reinfection in tuberculosis. Lancet Infect Dis 5:629-36.

Cohen T, Colijn C, Finklea B, Murray M, 2007. Exogenous reinfection and the dynamics of tuberculosis epidemics: Local effects in a network model of transmission. J Roy Soc Interface 4:523-31.

Coker R, McKee M, Atun R, Dimitrova B, Dodonova E, Kuznetsov S, Drobniewski F, 2006. Risk factors for pulmonary tuberculosis in Russia: Case-control study. Brit Med J 332:85-87.

CSA, 2007. The 2007 population and housing census of Ethiopia: Statistical report at country level. Central Statistical Agency, Addis Ababa, Ethiopia.

Dangisso MH, Datiko DG, Lindtjørn B, 2015a. Accessibility to tuberculosis control services and tuberculosis programme performance in southern Ethiopia. Global Health Action 8:29443.

Dangisso MH, Datiko DG, Lindtjørn B, 2015b. Spatio-temporal analysis of smear-positive tuberculosis in the Sidama zone, southern Ethiopia. PLoS One 10:e0126369.

Datiko DG, Lindtjørn B, 2009. Health extension workers improve tuberculosis case detection and treatment success in southern Ethiopia: A community randomized trial. PLoS One 4:e5443.

Escombe AR, Moore DA, Gilman RH, Pan W, Navincopa M, Ticona E, Martínez C, Caviedes L, Sheen P, Gonzalez A, 2008. The infectiousness of tuberculosis patients coinfected with hiv. PLoS Med 5:e188.

Esposito S, Tagliabue C, Bosis S, 2013. Tuberculosis in children. Medit J Hematol Infect Dis 5:e2013064.

Fares A, 2011. Seasonality of tuberculosis. J Global Infect Dis $3: 46$.

Ferrarini M, Spina F, Weckx L, Lederman H, De Moraes-Pinto M, 2016. Rate of tuberculosis infection in children and adolescents with household contact with adults with active pulmonary tuber- culosis as assessed by tuberculin skin test and interferon-gamma release assays. Epidemiol Infect 144:712-23.

Feske ML, Teeter LD, Musser JM, Graviss EA, 2011. Including the third dimension: A spatial analysis of tb cases in Houston Harris county. Tuberculosis 91:24-33.

Gelaw YA, Biks GA, Alene KA, 2014. Effect of residence on mothers' health care seeking behavior for common childhood illness in northwest Ethiopia: A community based comparative cross-sectional study. BMC Res Notes 7:1.

Getis A, Ord JK, 1992. The analysis of spatial association by use of distance statistics. Geogr Anal 24:189-206.

Harling G, Ehrlich R, Myer L, 2008. The social epidemiology of tuberculosis in South Africa: A multilevel analysis. Soc Sci Med 66:492-505.

Hirvonen K, Taffesse AS, Hassen IW, 2016. Seasonality and household diets in Ethiopia. Publ Health Nutr 19:1723-30.

Jia Z-W, Jia X-W, Liu Y-X, Dye C, Chen F, Chen C-S, Zhang WY, Li X-W, Cao W-C, Liu H-L, 2008. Spatial analysis of tuberculosis cases in migrants and permanent residents, Beijing, 2000-2006. Emerg Infect Dis 14:1413-9.

Kolifarhood G, Khorasani-Zavareh D, Salarilak S, Shoghli A, Khosravi N, 2015. Spatial and non-spatial determinants of successful tuberculosis treatment outcomes: An implication of geographical information systems in health policy-making in a developing country. J Epidemiol Global Health 5:221-30.

Lambert M-L, Hasker E, Van Deun A, Roberfroid D, Boelaert M, Van der Stuyft P, 2003. Recurrence in tuberculosis: Relapse or reinfection? Lancet Infect Dis 3:282-7.

Leung C, Yew W, Tam C, Chan C, Chang K, Law W, Wong M, Au K, 2004. Socio-economic factors and tuberculosis: A districtbased ecological analysis in Hong Kong. Int J Tubercul Lung Dis 8 958-64.

Li X-X, Wang L-X, Zhang H, Du X, Jiang S-W, Shen T, Zhang Y$P$, Zeng G, 2013. Seasonal variations in notification of active tuberculosis cases in China, 2005-2012. PLoS One 8:e68102.

Li X-X, Wang L-X, Zhang J, Liu Y-X, Zhang H, Jiang S-W, Chen J-X, Zhou X-N, 2014. Exploration of ecological factors related to the spatial heterogeneity of tuberculosis prevalence in PR China. Global Health Action 7:23620.

Lienhardt C, Fielding K, Sillah J, Bah B, Gustafson P, Warndorff D, Palayew M, Lisse I, Donkor S, Diallo S, 2005. Investigation of the risk factors for tuberculosis: A case-control study in three countries in West Africa. Int J Epidemiol 34:914-23.

Lienhardt C, Fielding K, Sillah J, Tunkara A, Donkor S, Manneh K, Warndorff D, McAdam KP, Bennett S, 2003a. Risk factors for tuberculosis infection in Sub-Saharan Africa. American J Respirat Crit Care Med 168:448-55.

Lienhardt C, Fielding K, Sillah J, Tunkara A, Donkor S, Manneh K, Warndorff D, McAdam KP, Bennett S, 2003b. Risk factors for tuberculosis infection in Sub-Saharan Africa: A contact study in The Gambia. Am J Respirat Crit Care Med 168:448-55.

Loudon RG, Spohn SK, 1969. Cough frequency and infectivity in patients with pulmonary tuberculosis 1 . Am Rev Respirat Dis 99:109-11.

Marais BJ, Gie R, Schaaf H, Hesseling A, Obihara C, Starke J, Enarson D, Donald P, Beyers N, 2004a. The natural history of childhood intra-thoracic tuberculosis: A critical review of literature from the pre-chemotherapy era [state of the art]. Int $\mathbf{J}$ Tubercul Lung Dis 8:392-402.

Marais BJ, Gie RP, Schaaf HS, Beyers N, Donald PR, Starke JR, 2006. Childhood pulmonary tuberculosis: Old wisdom and 
new challenges. Am J Respirat Crit Care Med 173:1078-90.

Marais BJ, Gie RP, Schaaf HS, Hesseling AC, Obihara CC, Nelson LJ, Enarson DA, Donald PR, Beyers N, 2004b. The clinical epidemiology of childhood pulmonary tuberculosis: A critical review of literature from the pre-chemotherapy era [state of the art]. Int J Tubercul Lung Dis 8:278-85.

Middelkoop K, Bekker L-G, Myer L, Dawson R, Wood R, 2008. Rates of tuberculosis transmission to children and adolescents in a community with a high prevalence of hiv infection among adults. Clin Infect Dis 47:349-55.

$\mathrm{MOH}, 2008$ Tuberculosis, leprosy and tb/hiv prevention and control programme manual. Ministry of Health, Addis Ababa, Ethiopia.

$\mathrm{MOH}, 2012$. Guidelines for clinical and programmatic management of tb, leprosy and tb/hiv in Ethiopia. Ministry of Heatlh Addis Ababa, Ethiopia.

$\mathrm{MOH}, 2013$. Annual tuberculosis bulletin 2013. Health Promotion and Diseases Prevention Directorate, Addis Ababa, Ethiopia.

Myers WP, Westenhouse JL, Flood J, Riley LW, 2006. An ecological study of tuberculosis transmission in California. Am J Public Health 96:685-90.

Nana YA, Noeske J, Dambach P, Bowong S, Fono LA, NgatchouWandji J, 2014. Spatial analysis of tuberculosis in Douala, Cameroon: Clustering and links with socio-economic status. Int J Tubercul Lung Dis 18:292-97.

Narasimhan P, Wood J, MacIntyre CR, Mathai D, 2013. Risk factors for tuberculosis. Pulmon Med 2013:828939.

Nava-Aguilera E, Andersson N, Harris E, Mitchell S, Hamel C, Shea B, López-Vidal Y, Villegas-Arrizón A, Morales-Pérez A, 2009. Risk factors associated with recent transmission of tuberculosis: Systematic review and meta-analysis [review article]. Int J Tubercul Lung Dis 13:17-26.

Newton SM, Brent AJ, Anderson S, Whittaker E, Kampmann B, 2008. Paediatric tuberculosis. Lancet Infect Dis 8:498-510.

Nnoaham KE, Clarke A, 2008. Low serum vitamin d levels and tuberculosis: A systematic review and meta-analysis. Int J Epidemiol 37:113-9.

Parrinello C, Crossa A, Harris T, 2012. Seasonality of tuberculosis in New York City, 1990-2007. Int J Tubercul Lung Dis 16:32-7.

Perez-Velez CM, Marais BJ, 2012. Tuberculosis in children. New England J Med 367:348-61.

Prasad A, Ross A, Rosenberg P, Dye C, 2016. A world of cities and the end of tb. Trans Roy Soc Trop Med Hyg 110:151-2.

Rao H-X, Zhang X, Zhao L, Yu J, Ren W, Zhang X-L, Ma Y-C, Shi Y, Ma B-Z, Wang X, 2016. Spatial transmission and meteorological determinants of tuberculosis incidence in Qinghai province, China: A spatial clustering panel analysis. Infect Dis Poverty 5:1.

Roba KT, O'Connor TP, Belachew T, O’Brien NM, 2015. Seasonal variation in nutritional status and anemia among lactating mothers in two agro-ecological zones of rural Ethiopia: A longitudinal study. Nutrition 31:1213-8.

Sherman SS, Hollis BW, Tobin JD, 1990. Vitamin d status and related parameters in a healthy population: The effects of age, sex, and season. J Clin Endocrinol Metab 71 405-13.
Shingadia D, Novelli V, 2003. Diagnosis and treatment of tuberculosis in children. Lancet Infect Dis 3:624-32.

Sia IG, Wieland ML, 2011. Current concepts in the management of tuberculosis. Mayo Clin Proc 86:348-61.

Souza WV, Carvalho MS, Albuquerque MdFP, Barcellos CC, Ximenes RA, 2007. Tuberculosis in intra-urban settings: A bayesian approach. Trop Med Inte Health 12:323-30.

Suk JE, Manissero D, Büscher G, Semenza JC, 2009. Wealth inequality and tuberculosis elimination in Europe. Emerg Infect Dis 15:1812-4.

Sun W, Gong J, Zhou J, Zhao Y, Tan J, Ibrahim AN, Zhou Y, 2015. A spatial, social and environmental study of tuberculosis in China using statistical and GIS technology. Int J Environ Res Public Health 12:1425-48.

Swaminathan S, Rekha B, 2010. Pediatric tuberculosis: Global overview and challenges. Clin Infect Dis 50:184-94.

Thorpe LE, Frieden TR, Laserson KF, Wells C, Khatri GR, 2004. Seasonality of tuberculosis in India: Is it real and what does it tell us? Lancet 364:1613-4.

Tiwari N, Adhikari C, Tewari A, Kandpal V, 2006. Investigation of geo-spatial hotspots for the occurrence of tuberculosis in Almora district, India, using GIS and spatial scan statistic. Int J Health Geogr 5:1.

Touray K, Adetifa I, Jallow A, Rigby J, Jeffries D, Cheung Y, Donkor S, Adegbola R, Hill P, 2010. Spatial analysis of tuberculosis in an urban west African setting: Is there evidence of clustering? Trop Med Int Health 15:664-72.

Triasih R, Robertson C, Duke T, Graham SM, 2015. Risk of infection and disease with mycobacterium tuberculosis among children identified through prospective community-based contact screening in Indonesia. Trop Med Int Health 20:737-43.

Tsai P-J, 2011. Spatial analysis of tuberculosis in four main ethnic communities in Taiwan during 2005 to 2009. Open J Prev Med $1: 125$.

Vynnycky E, Fine PE, 2000. Lifetime risks, incubation period, and serial interval of tuberculosis. Am J Epidemiol 152:247-63.

Wang T, Xue F, Chen Y, Ma Y, Liu Y, 2012. The spatial epidemiology of tuberculosis in Linyi City, China, 2005-2010. BMC Publ Health 12:885.

Webb AR, Kline L, Holick MF, 1988. Influence of season and latitude on the cutaneous synthesis of vitamin d3: Exposure to winter sunlight in boston and edmonton will not promote vitamin d3 synthesis in human skin. J Clin Endocrinol Metabol 67:373-8.

WHO, 2012. Global tuberculosis report 2012. World Health Organization, Geneva, Switzerland.

WHO, 2013. Roadmap for childhood tuberculosis: Towards zero deaths. World Health Organization, Geneva, Switzerland.

WHO, 2016. Global tuberculosis report 2016. World Health Organization, Geneva, Switzerland.

Willis MD, Winston CA, Heilig CM, Cain KP, Walter ND, Mac Kenzie WR, 2012. Seasonality of tuberculosis in the United States, 1993-2008. Clin Infect Dis 54:1553-60.

Woldeyohannes SM, Abera SY, 2015. Worldwide spatial and temporal distribution of tuberculosis (tb). J AIDS Clin Res 6:2. 